\title{
How Can I Contribute? Citizen Engagement in the Development of Nanotechnology for Health
}

\author{
Sikke R. Jansma (D) Anne M. Dijkstra • \\ Menno D. T. de Jong
}

Received: 19 January 2021 / Accepted: 15 November 2021 / Published online: 18 December 2021

(C) The Author(s) 2021

\begin{abstract}
Scholars and policymakers have increasingly advocated to engage citizens more substantially in the development of science and technology. However, to a large extent it has remained unknown how citizens can contribute to technology development. In this study, we systematically characterized citizens' contributions in the development of nanotechnology for health. We explored to which technology aspects citizens are able to provide suggestions on and on which values their suggestions are based. Fifty citizens in the Netherlands were asked to discuss different applications of nanotechnology for health. They were divided over eight focus groups, which lasted approximately $6.5 \mathrm{~h}$ each. The citizens were able to contribute to various technology aspects; they mainly focused on the technologies' implementation and use, they paid some attention to the development and system aspects, and also addressed, but less, the design and communication aspects. Their suggestions were often derived from concerns about the potential effects of the technologies and were predominantly based on the values of wellbeing, autonomy, and privacy.
\end{abstract}

Keywords Public engagement · Nanotechnology · Health technologies

S. R. Jansma $(\bowtie) \cdot$ A. M. Dijkstra $\cdot$ M. D. T. de Jong Department of Communication Science, Faculty of Behavioral, Management and Social Sciences, University of Twente, P.O. Box 217, Enschede 7500 AE, The Netherlands e-mail: s.r.jansma@utwente.nl

\section{Introduction}

Various scholars have stressed the importance of substantive public engagement efforts in the developmental processes of science and technology. They argued that the general public should be included in the development of technological innovations in order to create new knowledge and add social value [e.g., 1-3]. Wynne [2] underlined the importance of citizen engagement more than a decade ago, when he identified "an apparent institutional lack of ability to imagine that public concerns may be based on reasonable questions that are not being recognized and addressed" (p. 219). Eight years later, Jasanoff [1] remarked in her reflection on the development of public understanding of science that not much has changed. She concluded that too often the general public has been treated as an entity that is ignorant and indifferent to science, while in reality people can add relevant insights. In a similar vein, Rip [3] emphasized that responsible research and innovation (RRI) should not only be about a moral division in which scientists and other stakeholders promote progress and civil society actors add the 'responsible' components, but also that societal actors jointly should inquire issues that are at stake.

Although researchers agree upon the added value of the inclusion of citizens as a worthy partner in the development of science and technology, there has been criticism regarding the nature, design, and analysis of citizen engagement [4, 5]. Engagement 
activities too often stick to citizens' general perceptions of risks and benefits of nanotechnologies, thereby overlooking their contributions on broader ethical and social aspects of these technologies and specific values they might hold in relation with these technologies $[4,5]$. Hence, there is much to learn about the nature and content of citizens' input in this regard. Due to the complexity of technological innovations, the technicalities and the technologies' high degree of uncertainty and unpredictability [6], the question arises as to how the general public adds value to the development of technological innovations. In this study, we aimed to obtain more insights into citizens' contributions to future nanotechnologies for healthcare applications. In the following, we will elaborate on different rationales for public engagement, the role of citizens in the development of science and technology and the context of nanotechnologies for health.

\section{Public Engagement: From Informing to Co-creation}

The importance of engaging laypersons in the development of science and technology has been recognized for years, but the perspective of why and how to engage publics has changed [7]. Due to citizens' increasingly critical views on technological developments, public engagement started in the 1970s as a way of informing and persuading the public about technological developments. This was based on the deficit model: it was assumed that these critical views towards science and technology were based on a lack of knowledge. That assumption changed in the 1990s when various studies showed that informing or persuading citizens did not suffice to increase acceptance for technological change because the relation between knowledge and attitude was much more complex [8]. To increase citizens' trust in novel technologies and enhance legitimacy of their governance, a dialogue model was adopted based on the idea that two-way communication between science and society would restore this trust $[7,9]$. Although the value of a dialogue between science and society has been recognized, the debate on genetically modified organisms (GMOs) in Europe showed that the crisis of public trust in the technology was so deep that also the view on restoring citizens' trust in science and technology started to change [10]. Instead of technocratic governance of technology and top-down public participation, emphasis was put on including societal norms and values in the development of science and technology through public engagement [10].

The emphasis on inclusion of societal norms and values during the innovation process and the reflection on potential societal impacts of technological innovation has been labelled as responsible research and innovation (RRI) [11]. Public engagement is considered a means to increase legitimacy of the innovation process and to create more socially robust innovations. Based on this view, new types of engagement, such as co-creation and co-production, have increasingly gained attention by researchers and policymakers. These types aim for substantial contributions of citizens when developing innovations [12-16]. The European Commission [12], for instance, regards public engagement in RRI a means to "co-creating the future with citizens and civil society organizations, and also bringing on board the widest possible diversity of actors that would not normally interact with each other, on matters of science and technology" (par. 1). Various calls within the Horizon 2020 programme, the European Commission's main funding programme for European research and innovation between 2014 and 2020, have promoted co-creation with different types of actors, including citizens [14].

The idea of including different types of knowledge, other than those of experts, when co-creating technological innovations has existed for a longer time, but the focus was mainly on including end-users and not citizens. For instance, Von Hippel [17] solely referred to the end-users when he defined his concept of 'democratization of innovation'. Similarly, Prahalad and Raswany [18] and Vargo and Lusch [19] studied the added value of end-users in the development of innovations. In these contexts, co-creation is based on an economic rationale initiated by organizations to produce goods or services that are more efficient and effective rather than the creation of socially robust innovations. Also, in the area of medical research, end-users have been involved in the development of health technologies. For instance, patient organizations were active in shaping the agenda of research in fields of their concern [7], patients were involved in the creation of clinical guidelines [20], and care-pathways were co-created with patients [21]. Although these studies provide relevant insights in public engagement, they address a type of public that has a clear relation 
with the technology and can, thereby, provide expertise from a user's perspective [21]. The affected public of technological innovations which can have a major influence on society, such as nanotechnology, can be every citizen. In order to develop such technologies in a more socially robust way, as emphasized in RRI, it is, therefore, not only relevant to engage end-users, but also citizens.

Citizens and the Development of Science and Technology

Some scholars have studied citizens' contributions to technological innovations and concluded that involving citizens in the innovation process has the potential to create more benefits than simply enhanced inclusion and accountability. Although citizens might not understand all technicalities of an innovation, they are able to formulate their needs, define conditions for use, and understand the innovation's potential societal impact [13, 14, 22-24]. For instance, Lehoux et al. [24] found in their study on future health technologies that citizens were able to define the context in which the technologies should be implemented. Citizens emphasized that the technologies should be embedded in professional care and that individual freedom and privacy should be protected [24].

Furthermore, citizens can provide novel insights into research and innovation since they may differ in their perspectives from experts. Repo and Matschoss [25] found in their comparison of experts' and citizens' vision of the future European research priorities that both groups approach the future from largely different perspectives. Citizen participation could, therefore, potentially disrupt traditional research and innovation agendas and challenge conventional practices that rely on established norms defined by experts. For instance, in a European Horizon 2020 project CIMULACT, citizens were able to give unique input to the EU research and innovation agenda by defining their visions and desirable futures [13]. Additionally, issues that might hamper the acceptance of an innovation can be identified, because citizens tend to be both more precautionary and more cautious than experts regarding the potential personal, social and environmental consequences of innovations [26].
Although the studies provided insights in the added value of engaging citizens in the development process of science and technology, a more systematic analysis of how citizens can contribute is lacking. Since citizens have different perspectives than experts and add novel insights to the process, it is important both from a practical and scientific point of view to get a better understanding of the nature and characteristics of citizens' contributions.

\section{The Context of Nanotechnology}

Nanotechnology provides an interesting context for studying citizens' contributions, as it is considered a promising technology, but its impact on society is unpredictable [6,27]. Due to its potential impact on society, it has become the leading field for activities and discussions about RRI [3]. Nanotechnologies act as the basis for technology solutions across a range of industrial and societal challenges [28]. In the context of health, these solutions include new therapeutic interventions, new ways of monitoring health, new ways of diagnosing diseases, and personalized and targeted medicines. Although many products already contain nanoparticles (e.g. transparent sunscreen, scratch-resistant coatings and water-repellent clothing), innovations that might radically change our society are still in their developmental phase. These innovations are often disconnected from the people who will be affected by them because they are being developed in laboratories and other secluded arenas [29]. Hence, there is a need to engage the public in the development and implementation of nanotechnologies.

Although insights and knowledge have been collected on public engagement exercises in the field of nanotechnology [3, 27, 30, 31], little attention has been paid to understanding the outcomes of these initiatives for the research and development of specific nanotechnologies [30]. Various studies have provided lessons learned regarding the organization of public engagement initiatives about nanotechnology. Dijkstra and Critchley [30], for example, emphasized that deliberations about nanotechnologies should include the potential risks and benefits of their applications, because publics find both aspects important. Wickson et al. [31] emphasized the diverse nature of nanotechnology and stated that public engagement activities should focus on 
specific applications rather than on nanotechnology in general. Delgado et al. [27] advocated more upstream engagement activities, where empowered citizens provide input to the development of nanotechnologies. However, the authors warned that public awareness of nanotechnology is low. Therefore, they argued that engagement with citizens should be initiated by actors involved in nanotechnology (e.g. government, research, civil society organizations) and that citizens should be informed through visions or scenarios about future applications of nanotechnology [27]. While these findings provide relevant input for the setup of engagement exercises, there is a need to focus on the outcomes of public engagement and their (potential) effects on the development and implementation of the science or technology at hand [1,32].

\section{Research Question}

In this study, we aim to gain insights into citizens' contributions to the development of nanotechnologies for healthcare applications. We are interested in the aspects citizens could give suggestions to and the values underlying these suggestions. Within the context of health, some scholars have differentiated multiple aspects of technology development to obtain a better understanding of people's potential experiences with the technology. These aspects include the 'design' connected to the artefacts of the technology, 'development' connected to the developmental process of the technology, 'implementation' connected to how the technology is implemented and how the actors are involved in this process and 'utilization' connected to the aims of the technology and how it is being used [33, 35]. These four aspects correspond with the technological innovation system (TIS) perspective on technologies, which approaches innovations as a socio-technical system and focuses on the activities in the development, diffusion, and utilization of new technologies [35]. In this study, we use the four aspects of design, development, implementation and utilization as an analytical framework to obtain a better understanding of citizens' contribution to the development of nanotechnologies for healthcare applications.

Furthermore, to understand how citizens contribute to the development of nanotechnologies, we analysed the underlying values. Most approaches to RRI emphasize that to be responsible, research and innovation need to address societal needs and challenges, anticipate potential problems and reflect on underlying values [36]. Porcari et al. [37], who developed a roadmap for RRI, identified typical moral values that are important for research and innovation, such as autonomy, freedom, dignity, privacy, justice, well-being and responsibility.

\section{Method}

Design

This study addresses citizens' contributions to the development of nanotechnology in a systematic way, by analysing to what technology aspects citizens are able to contribute to and based on what values. Eight extensive focus groups, which lasted approximately $6.5 \mathrm{~h}$ each, with six to seven participants per focus group, and a total of 50 participants, were organized in the Netherlands. The focus groups were organized as part of the European Horizion 2020 project GoNano. Following the insights of Wickson et al. [31], who stated that public engagement activities should focus on specific applications rather than on nanotechnology in general, we selected future health applications of nanotechnology as input for the focus groups. The focus groups were moderated by trained professionals, and the setup of the sessions was derived from design-thinking methodology. This methodology included four phases of exploration, ideation, prototyping and reflection, which, together, foster creativity and promote integration of different types of knowledge [38, 39]. In the exploration phase, participants get to know each other and the topic. The ideation phase stimulates generating new ideas, which are further developed in the prototyping phase. In the reflection phase, participants reflect upon the output and process.

\section{Future Applications of Nanotechnology}

Based on a literature review and five interviews with Dutch experts from various sectors (a director of a research institute on nanotechnology, two senior 
policy advisors from the Ministry of Health, a senior advisor of a CEO of a technological start-up, and a head of innovation of a CSO), three of the most promising nanotechnologies in health were selected. These technologies included (early-) diagnostic devices, sensor technology for monitoring diseases and regenerative medicines. Furthermore, several application contexts were defined, including the detection and treatment of cancer, monitoring and treatment of diabetes and preventive healthcare. Based on the technologies and the applications areas, three future scenarios that can unfold in 2030 in the healthcare context were developed (see Appendix). These scenarios were written up as short stories (265-333 words) and illustrated with cartoons. They were distributed to the participants one week before the session and at the start of the focus groups. The use of scenarios follows the research of Lehoux et al. [24], who studied the public's perception of the relationship between responsibility and prospective health technologies by means of scenarios.

\section{Instrument}

The focus groups were divided in several phases related to the design thinking methodology. First, the participants were asked to respond to future applications of nanotechnologies for health that were provided through the scenarios. This corresponded with the exploration phase of design thinking, and participants became familiar with the technologies. Second, the participants were asked to give specific suggestions for the applications that were mentioned in the scenarios, which corresponded with the ideation phase. Third, based on the suggestions of the previous sessions, the participants had to design their ideal technology, which was the prototyping phase. Fourth, the participants were asked to reflect on the input given in the previous phases and to formulate messages for various stakeholders involved in the development of the technologies. The aim of these phases was to gain insights into the needs and values of citizens and to collect new suggestions for the development of future health nanotechnologies.

\section{Participants}

Dutch citizens (non-experts), who lived in different areas in the Netherlands, who were of different ages, mostly highly educated, and who were represented by an almost equal number of men and women, participated in this study (see Table 1). The participants were recruited through leaflets in public places, social media posts and news items on websites of various health organizations and through diverse networks of the researchers. Initially 55 participants signed up to participate in the study, but 5 participants cancelled last-minute. The participants were divided into eight groups based on their demographic characteristics, with the aim of creating diverse groups.

Analysis

Seven focus group sessions were recorded and transcribed. One session was not recorded due to a failure of technology, but the moderator took extensive notes. The transcripts consisted of discussions about the scenarios, messages to stakeholders and explanations of the 'ideal technology'.

Coding was conducted by the first author and consisted of two rounds. In the first round, the technology aspects to which the participants provided suggestions for were coded. These aspects were derived from the literature $[33,34]$ and included design, development, implementation and utilization. During the coding, it became clear that in addition to these four aspects, suggestions were given to two other aspects: 'embeddedness in healthcare system' and 'communication about the technology'. Comments about the embeddedness of technology in the healthcare system were both

Table 1 Participant characteristics

\begin{tabular}{lll}
\hline & $N$ & Percent \\
\hline Gender & & \\
Male & 27 & 54 \\
Female & 23 & 46 \\
Age & & \\
$18-24$ & 7 & 14 \\
$25-34$ & 17 & 34 \\
$35-49$ & 8 & 10 \\
$50-59$ & 9 & 18 \\
$60+$ & 9 & 18 \\
Education & & \\
Low (primary education, secondary & 0 & 0 \\
$\quad$ vocational education) & & \\
Middle (high school) & 6 & 12 \\
High (university, applied university) & 44 & 88 \\
\hline
\end{tabular}


about the context (system) in which the technologies were being developed and how the technologies could change the system. Comments regarding communication about the technology were about providing information and educating citizens about the technology. Furthermore, the participants did not discuss for which aims the technologies could be used, which would be the 'utilization aspect', but focused on whether they wanted to make use of the technologies. Therefore, we changed 'utilization' into 'use' (see Table 2).

The unit of analysis of the codes was the whole text part from the transcribed discussion of a particular focus group session that referred to a particular technology aspect. These text parts consisted of three to 20 sentences and were both based on input from one participant or multiple participants within one focus group session. In total, 328 text parts were coded that referred to a particular technology aspect.

In the second round, the values to which the suggestions on the technology aspects could be connected to were coded. They can be seen as the underlying motives for the suggestions. The values were inductively coded and included well-being, autonomy, privacy and security of data, accessibility, affordability, safety and health (see Table 2). The unit of analysis was every text part that referred to a particular value, which was between one and five sentences. Those text parts co-occurred with a larger text part that referred to a particular technology aspect. However, not every text part referring to a technology aspect contained a reference to a value. In total, 301 text parts were coded that referred to a value.

To indicate measurement consistency, inter-coder reliability was based on $10 \%$ of the corpus. One round of coding was conducted with a social sciences researcher who was not involved in this study. This resulted in a good and moderate agreement (Cohen's kappa) on the two coding categories (see Table 2).

\section{Results}

The results are based on all the contributions from the focus group sessions, without connecting them to the specific phases of the focus groups.

\section{Aspects of Nanotechnologies}

The participants gave feedback on the six distinguished aspects of the nanotechnologies: implementation, use, system, development, design and communication (see Table 3), with the main emphasis in all eight focus groups being on the implementation of nanotechnologies and the use of these technologies. Moderate attention was given to suggestions on the healthcare system and the development of nanotechnologies, and the least emphasis was placed on the design of nanotechnologies and communication about nanotechnologies.

When discussing the 'implementation' and 'use' of nanotechnologies, the participants mainly referred to monitoring and diagnostic devices. Three main subjects were associated with the implementation aspect: (1) who should operate the technology (e.g. health professionals or citizens themselves), (2) accessibility to the technology (e.g. everyone, voluntary access and frequency of access), and (3) how health data should be managed in relation to privacy and security. These subjects often related to the participants' concerns about a decrease in well-being. When the participants referred to the 'use' aspect of the technologies, they often discussed whether they wanted to use the technologies from their own perspective. In this regard, the fear that the technologies would have a negative influence on well-being was mentioned. Additionally, some, but fewer, references were made to how the technologies could improve their health and whether the technologies were safe to use.

The participants referred to 'embeddedness in the healthcare system' and 'development' of nanotechnologies when they mentioned criteria to be taken into account to make future healthcare and health technologies acceptable. Discussions about the healthcare system were often related to the possibility of transforming the system from treatmentbased healthcare to preventive healthcare. The participants agreed that keeping healthcare affordable and, therefore, accessible to everyone should be the main motivation. In relation to the development of nanotechnologies, the participants discussed criteria to be taken into account by researchers and businesses. The participants emphasized that in the developmental process, these actors should focus on the potential societal implications of the technology, the safety of the technologies for the environment, the use of the technology and the data generated by the technology.

The participants provided also suggestions for the design of and communication about nanotechnologies. The contributions that were given regarding 
Table 2 Codebook

\begin{tabular}{|c|c|c|c|}
\hline Category & Cohen's kappa & Code & Description \\
\hline \multirow[t]{6}{*}{$\begin{array}{l}\text { Aspects of } \\
\text { the tech- } \\
\text { nology }\end{array}$} & \multirow[t]{6}{*}{0.94} & Development of the technology & $\begin{array}{l}\text { About future technologies or technological directions that might } \\
\text { or could be developed/ethical aspects of the development of } \\
\text { technologies/references to research/and advice or messages to } \\
\text { developers and/or researchers }\end{array}$ \\
\hline & & Design of the technology & $\begin{array}{l}\text { Suggestions or comments about the design of a specific } \\
\text { technology, reading device or interface of a technology/ } \\
\text { comments about possible features and settings of a } \\
\text { technology and its reading device/explanation of the } \\
\text { design of a 'new' or 'ideal' technology }\end{array}$ \\
\hline & & Implementation of the technology & $\begin{array}{l}\text { How the technology could be implemented/how different } \\
\text { stakeholders are included in the care loop and who will } \\
\text { operate the technology/where the technology will be used } \\
\text { or can be purchased/frequency of use of the technology } \\
\text { (yearly, daily)/whether the technology is prohibited or not/ } \\
\text { and who will pay for it }\end{array}$ \\
\hline & & Use of the technology & $\begin{array}{l}\text { Only about intentions or attitudes regarding the willingness } \\
\text { to use or not to use the technology, and argumentation or } \\
\text { motives for the intention/influence of use of the technology } \\
\text { on well-being/often described from an individual perspective }\end{array}$ \\
\hline & & Communication about the technology & $\begin{array}{l}\text { Suggestions related to communication and education about } \\
\text { the technology on an individual level, organizational level } \\
\text { and societal level }\end{array}$ \\
\hline & & $\begin{array}{l}\text { Embeddedness of the technology in } \\
\text { the healthcare system }\end{array}$ & $\begin{array}{l}\text { Comments on the healthcare system and regulatory framework: } \\
\text { how the healthcare system regulations should be changed if } \\
\text { the technology were to be implemented or how the technology } \\
\text { could change the healthcare system/often connected to the role } \\
\text { of the government and insurance companies in the healthcare } \\
\text { system/described on a generic level }\end{array}$ \\
\hline \multirow[t]{7}{*}{ Values } & \multirow[t]{7}{*}{0.68} & Well-being & $\begin{array}{l}\text { Whether the technology increases or decreases well-being (a } \\
\text { state or condition of happiness), including whether the use } \\
\text { of it leads to stress and anxiety }\end{array}$ \\
\hline & & Autonomy & $\begin{array}{l}\text { Whether the technology provides self-determination over the } \\
\text { body and ownership of data and whether (potential) users } \\
\text { have the freedom of choice in using the technology }\end{array}$ \\
\hline & & Privacy and security of data & $\begin{array}{l}\text { Whether the technology collects and stores data and whether } \\
\text { it provides possibilities for sharing data in a secure and } \\
\text { safe way }\end{array}$ \\
\hline & & Affordability & $\begin{array}{l}\text { Whether the technology is affordable to purchase and other } \\
\text { financial aspects related to the technology and the healthcare } \\
\text { system }\end{array}$ \\
\hline & & Accessibility & $\begin{array}{l}\text { Whether the technology safeguards or enhances accessibility } \\
\text { to healthcare and health or whether it leads to polarization } \\
\text { (poor vs. rich, old vs. young, digital skilled vs. unskilled) }\end{array}$ \\
\hline & & Safety & $\begin{array}{l}\text { Whether the technology is safe to use, including the interpretation } \\
\text { and reliability of data and potential harmful consequences }\end{array}$ \\
\hline & & Health & $\begin{array}{l}\text { Whether the technology improves (physical) health, including } \\
\text { treatment of diseases }\end{array}$ \\
\hline
\end{tabular}


Table 3 Frequency of coded the text parts that refer to technology aspects

\begin{tabular}{|c|c|c|}
\hline Aspect & Frequency & Illustrative quote \\
\hline Implementation & 101 & $\begin{array}{l}\text { "I get the impression that these monitoring and diagnostic devices lead to self-medication, which I } \\
\text { dislike. There are so many people who are not able to do this, so we should ensure that a medical } \\
\text { professional operates the technologies." }\end{array}$ \\
\hline Use & 92 & $\begin{array}{l}\text { "I believe that I would live constantly in fear about my health if I were to use such a monitoring } \\
\text { device. You never know when an anomaly will be detected. This also relates to the reliability of the } \\
\text { technology. How do you know for sure that the data are measured in a reliable way?" }\end{array}$ \\
\hline System & 55 & $\begin{array}{l}\text { "Imagine if everyone were to make use of these monitoring and } \\
\text { diagnostic devices. It would probably place a huge burden on the healthcare system, both financially } \\
\text { and in terms of labour, as all these people would go to a health professional in case of bad results." }\end{array}$ \\
\hline Development & 47 & $\begin{array}{l}\text { "When developing these technologies, researchers should take into account the human dimension. } \\
\text { People should not be treated as 'objects' that need be cured but as human beings. This will enhance } \\
\text { societal acceptance." }\end{array}$ \\
\hline Design & 23 & $\begin{array}{l}\text { "I would find it much more logical if the monitoring device were to only give a signal if something } \\
\text { were wrong, and thereby would not continuously focus attention on your health. But this is more of a } \\
\text { technical solution, of having the sensors in your body, but not being continuously aware of them." }\end{array}$ \\
\hline Communication & 10 & $\begin{array}{l}\text { "I don't think we can stop these technological innovations. Therefore, I believe we should educate and } \\
\text { inform citizens, in order to prepare them for making decisions about the use of these technologies." }\end{array}$ \\
\hline
\end{tabular}

the design aspect mainly related to the reading of the monitoring and diagnostic devices on which the data would be displayed. The participants connected their suggestions to an increase in well-being (i.e. a design that prevents being constantly aware of health data) and safety (i.e. little room for misinterpretation and ambiguity in reading the data). Suggestions about the communication aspect were about how to inform and educate the general public about the nanotechnologies. These suggestions mainly involved increasing societal acceptance and empowering citizens in making informed decisions about whether to make use of the technologies.

\section{Technology Aspects and Underlying Values}

To get more insights in the content of the participants' contributions to the technology aspects, we analysed for the values related to these aspects. The participants mentioned various values in the context of future nanotechnologies, including wellbeing, autonomy, privacy and security, affordability, accessibility, safety and health. These values were mentioned across various technology aspects, but some values were more often stated in relation to a particular aspect than other values (see Table 4).

Table 4 Co-occurrence of technology aspects and values

\begin{tabular}{llllllll}
\hline Values & Well-being & Autonomy & Privacy+security & Affordability & Accessibility & Safety & Health \\
\hline Aspects & & & & & & & \\
Implementation & 16 & 28 & 20 & 9 & 18 & 9 & 10 \\
Use & 34 & 12 & 8 & 7 & 8 & 13 & 13 \\
System & 2 & 11 & 9 & 19 & 8 & 2 & 5 \\
Development & 2 & 2 & 4 & 3 & 2 & 6 & 2 \\
Design & 7 & 1 & 2 & 0 & 0 & 4 & 0 \\
Communication & 0 & 3 & 0 & 0 & 0 & 0 & 0 \\
Total & $\mathbf{6 1}$ & $\mathbf{5 9}$ & $\mathbf{4 3}$ & $\mathbf{3 8}$ & $\mathbf{3 6}$ & $\mathbf{3 4}$ & $\mathbf{3 0}$ \\
\hline
\end{tabular}




\section{Well-being}

Well-being was most frequently referred to in the focus groups, and it was mainly related to the use aspect and, to a lesser extent, to the implementation aspect of monitoring and diagnostic devices. Regarding the early diagnostic devices, a number of participants were concerned that insights into the high risk of diseases in an early stage would negatively affect their well-being. Therefore, they doubted whether they wanted to make use of such a device. This was especially the case for diseases for which no cure has been developed yet (e.g. Alzheimer's disease). Additionally, a majority of the participants thought that diagnostic devices that have to be operated by patients at home could lead to stressful situations, as citizens might not know how to deal with negative outcomes. A few participants compared the devices to a home-test for sexually transmitted diseases (STDs), which are already on the market, but which they did not want to use, because they are afraid of the outcomes. The participants suggested that when implementing the technology, the health professional should operate the diagnostic devices because he/she can provide mental care and solutions for a treatment plan in case of negative outcomes.

When discussing monitoring devices, almost all the participants agreed that they disliked the idea of being constantly aware of generated health data. They thought that even though awareness of health data could lead to a better lifestyle and, therefore, improve their health, it would negatively influence their well-being. Hence, they were hesitant to make use of the devices. One of the participants stated, "I wouldn't want to use it, I would go mad if I would be aware of my health every day" (Respondent 4, Group 2). A suggestion was made to design the monitoring device in such a way that users would only obtain a signal when an anomaly was detected. Various participants compared the device with news apps, which give push messages in case of important news events. Additionally, some participants suggested implementing monitoring technologies in such a way that the data generated by the technology would be linked to a reading device that is operated by a health professional who interprets the data and informs the user.

\section{Autonomy}

Autonomy was often referred to in relation to the implementation aspect, as well as to the use and system aspects. Several participants emphasized that freedom of choice in using nanotechnologies for health should be safeguarded at all times. Others challenged this notion by making a comparison with vaccinations and thought that some technologies should be made mandatory if public health would be in danger. These aspects relate to the implementation of nanotechnologies. The debate about freedom of choice arose from the fear that the government or health insurance companies could force the use of early diagnostic and monitoring technologies to transform the healthcare system from treatment-based care to preventive healthcare (system aspect). One participant, for example, stated, "these technologies might potentially lead to an unjust society, where the insurance company can decide what you need to do" (Respondent 3, Group 4).

Furthermore, autonomy was mentioned in relation to the implementation aspect of monitoring and diagnostic devices. Some participants thought that it would be a good development if citizens had more control in using and operating health technologies, since it would provide them with more autonomy. The participants made a link to pregnancy tests, which they said empowered women. Others thought that citizens' autonomy in operating health technologies should be limited and that the health professional should be included in the care loop, for the sake of citizens' well-being (less awareness of health data) and to prevent misinterpretations of data.

\section{Privacy and Security of Health Data}

Additionally, the privacy and security of health data were mainly linked to monitoring and diagnostic devices in relation to the implementation, the system and use aspects. Many participants were afraid that the data generated by these devices would be 
shared with health insurance companies, who could take advantage of the data to adjust their premiums (system aspect). An illustrative comment made by one of the respondents was that "I believe it [the monitoring device] is very sensitive for privacy issues. What if health insurance companies will pay the producers of the device and will get access to the data? Who will safeguard this?" (Respondent 1, Group 1). Some participants made an analogy with the electronic patient record, which has a controversial history in the Netherlands. The participants brought up that when developing monitoring and diagnostic devices, developers should ensure that the data are collected and stored in a secure way. Additionally, when implementing the technology, the government should ensure that citizens own their data themselves and can decide whom to share it with.

\section{Affordability}

Every participant emphasized that the technologies should be affordable for everyone, and this value was often mentioned in relation to the system aspect. For instance, the possibility of transforming the healthcare system from treatment-based healthcare to more prevention-based healthcare with monitoring and diagnostic devices was discussed and whether this would decrease or increase the financial burden. Some participants argued such transformation would decrease costs, since diseases would be diagnosed at an earlier stage and the lifestyle could be better adjusted. Other participants thought that such a transformation would make healthcare more expensive, because people would become more aware of their health. Building further on this discussion, the participants emphasized that an important criterion for using nanotechnologies is whether they safeguard or increase the affordability of healthcare.

\section{Accessibility}

Many participants emphasized that health technologies should be accessible for everyone and should not lead to polarization in society, which was mainly related to the implementation of nanotechnologies. The participants feared potential polarization in two domains: rich versus poor and digitally skilled people versus people who are not digitally skilled. When implementing expensive technologies such as regenerative medicines, the technologies should be available to everyone and not only to the rich. Some participants compared the new technologies with donor organs and argued that in the case of limited availability, access to regenerative medicines should be decided based upon health indicators and not based upon financial means. Furthermore, a number of participants were afraid that monitoring and diagnostic devices that required the skills of people to read and interpret the data might limit access to these technologies for less educated and less digitally-skilled people. Therefore, the participants advocated including the health professional in the care loop when implementing the device. One of the participants argued that "you need to have a certain level of intelligence to understand the data provided by this technology. A general practitioner can give you a clear consultation based on the data, but the technology itself can't” (Respondent 3, Group 2).

Safety

Safety was less frequently mentioned. When the participants referred to safety, they often related it to the use and implementation aspects. They discussed whether it was safe for their health to use monitoring and diagnostic devices, as they were afraid that the data would not be reliable or could lead to misinterpretations. Some participants therefore thought it was safer to implement the devices in a healthcare context. An illustrative comment about this value is the following: "I believe researchers should take into account the reliability issue of data. Citizens don't know how to deal with this" (Respondent 1, Group 4). Additionally, the participants had doubts about the safety of using regenerative medicines, because they had little knowledge about them. One participant said, for example, "personally, I wouldn't make use of it because you don't know what the risks are. Before bringing such a technology [regenerative medicines] to the market, you need to have more knowledge about the risks" 
(Respondent 6, Group 2). The participants also were concerned about the impact of nanotechnologies on the safety in relation to the environment, and they emphasized that nanotechnologies should be developed in an environmentally-friendly and sustainable way.

\section{Health}

The participants also hardly mentioned 'health' as a value. When the participants referred to health, it was mainly related to the use and implementation of monitoring and diagnostic devices and connected to preventive healthcare. Some participants hesitated to make use of these devices, as they doubted whether the use would improve their health. The participants feared that people would only rely on the technology and no longer on their intuition. One of the participants made a comparison with navigation systems: "It is similar to navigation systems that calculate your route, and we just blindly follow the instructions" (Respondent 2, Group 1). Others saw clearly added value of the technologies for their health. One respondent said, "a focus on preventive health seems really valuable to me, you know immediately when something is wrong and can anticipate" (Respondent 2, Group 2).

\section{Discussion}

We summarize and interpret the main findings of this study below. Subsequently, we address the limitations of the study and propose directions for future research. The section ends with the implications and recommendations that follow from our findings.

\section{Main Findings}

In the extensive focus groups on nanotechnologies for healthcare applications, the participants deliberated on a broad range of technology aspects. The participants provided most suggestions on the 'implementation' and 'use' aspects. When referring to these aspects, they often imagined themselves as users of the nanotechnology applications.
They argued whether they wanted to make use of the technologies or not (use aspect) and defined the circumstances and conditions under which they were willing to use them (implementation aspect). Furthermore, the participants substantially contributed to the 'embeddedness of the technology in the system' and the 'development' aspects. When they discussed these aspects, they related them to the consequences nanotechnologies might have for society as whole. This shows that the participants were not only able to imagine the consequences of nanotechnologies for their personal life, but that they are also able to comment on a higher level of abstraction. Less attention was given to the 'design' and 'communication' aspects. The design aspect was mainly connected to technological artefacts. Although the participants were able to provide some suggestions on how to design the interface of monitoring devices, they hardly discussed other technical aspects of nanotechnologies. This might be due to their lack of knowledge about nanotechnology, which was also discussed in relation to the communication aspect, when the participants addressed the need for information and education about the working principles of nanotechnologies.

The suggestions on the technology aspects were based on a number of underlying values. When looking at these values, all the values were substantially referred to, but the frequency of the values differed per technology aspect and was mostly based on the participants' concerns. Regarding the implementation aspect of nanotechnologies, autonomy and privacy and security were most often referred to. The participants emphasized that freedom of choice should always be provided in using nanotechnologies for health and that users of technologies that generate health data should have ownership of their data. Also, when referring to the communication aspect, the participants emphasized the importance of autonomy. In relation to the use and design aspects, well-being was mentioned the most. The participants worried that using monitoring and diagnostic devices might lead to continuous awareness of health indicators. They came up with a number of design 
suggestions to prevent this continuous awareness and to increase well-being. Affordability of health technologies was an important value in the context of the system aspect, as the participants had concerns regarding the financial burden the technologies might place on the system. With regard to the development aspect, 'safety' was mentioned the most. The participants emphasized that developers of nanotechnologies should make sure that these technologies are safe to use and safe for the environment.

Interestingly, most of the suggestions were given in relation to monitoring and diagnostic devices. The participants found it much easier to understand the working principles of these technologies and were better able to relate them to their own lives than they did to the regenerative medicines. When discussing monitoring and diagnostic devices, the participants made various analogies with existing technologies that they were familiar with, such as the benefits and negative aspects of pregnancy tests, electronic patient files, navigation systems and vaccinations.

\section{Theoretical Implications}

Our research shows that citizens can valuably contribute to the development and implementation of technological innovations. Although some scholars have already emphasized the added value of citizens in the development of technologies [1, 12], they have mainly emphasized that citizens are able to judge the acceptability and desirability of potential consequences. Our study shows that citizens are able to give specific suggestions to a variety of aspects of technologies, including their use, implementation, embeddedness in the system, development, design and communication about the technologies. This shows that citizens are able to judge the effects of the technologies on different levels of abstraction: the consequences of the technologies for their personal life as well as the consequences of the technologies for society.

Furthermore, by distinguishing the different technology aspects, a more systematic picture of the nature of the citizens' contributions can be drawn.
Citizens' suggestions of the nanotechnologies were mainly based on their concerns regarding these technologies and could be related to a number of underlying values. The importance of these values differs per technology aspect. Previous studies have examined citizens' input regarding nanotechnologies in different contexts, but often stick to traditional promises about progress and risk discourses [4]. For instance, several studies have addressed citizens' risks perceptions regarding nanotechnologies, often in relation to safety and health [e.g. 30, 40-43]. These studies thereby ignore the reflection on broader ethical and social impacts of emerging technologies, as well as nuances in how citizens position themselves with regard to these technologies [4]. Our study provides a good insight in the capacity of citizens to reflect on the broader societal impacts of nanotechnologies and also provides a nuanced picture of citizens' perceptions, beyond accepting or rejecting nanotechnologies and their applications. As such, it provides a framework to approach nanotechnologies in a multi-dimensional way, based on different technology aspects, which can be used to set up and analyse citizen engagement activities.

It should be noted that, although participants were able to contribute to future nanotechnologies in health, their ability to provide suggestions differed per application. The participants mainly provided suggestions on technologies that they could relate to in their daily lives, and they used analogies with existing technologies to do so. These findings are in line with previous studies, which indicate that citizens use analogies with familiar objects, notions and technologies as a sense-making strategy [44, 45]. However, as Schwarz-Plaschg [46] noted, analogies are not just used for sense-making but are also a rhetorical strategy used by citizens to strengthen their suggestions and arguments.

\section{Limitations and Future Research}

Some limitations of this study must be taken into account. First, the participants were predominantly highly educated. While the participants were able to give their suggestions on different aspects of 
nanotechnologies, less educated participants might have had more difficulties in doing so. Second, the sample consisted of 50 participants, who were equally divided based on age, gender and (rural/ urban) living area. However, there are other variables that could also influence participants' opinions. Jasanoff [1] reminded us in her essay that there is no such thing as the 'public', which we should be aware of when generalizing results. Nevertheless, the qualitative research setting of this study with 50 participants divided over eight groups provides a great number of participants to draw conclusions from. Third, the participants had little knowledge about the discussed nanotechnologies, which is why we used scenarios to inform them about these technologies. Different characteristics of the technologies were highlighted in the scenarios, but it is difficult to formulate the scenarios in a totally neutral way, and this may have influenced the discussions. Nevertheless, the participants were free to choose the focus of the discussions and selected the issues they wanted to discuss themselves. The descriptions of the scenarios can be found in the Appendix. Fourth, while this study gave clear insights in the characteristics of citizens' contributions in the development of nanotechnologies for health, it did not assess how these contributions influenced the actual development of these technologies. The question of how citizens affect science and their agency in technology development was beyond the scope of this study. The EU Horizon 2020 project GoNano, in which our study was conducted, took into account the broader processes of science and technology development. For instance, the outcomes of these focus groups were mentioned in policy briefs and were used as input for co-creation sessions with stakeholders [47]. However, the project did not reflect upon the role and agency of citizens and it would be interesting for future research to study and reflect on the bigger system and power structures that allow or prevent citizens from contributing to actual science and technology development.

\section{Conclusion}

In an open discussion about nanotechnologies for health applications, citizens were able to provide suggestions for a variety of technology aspects, including the implementation, use, design, system, development and communication aspects. Citizens' contributions were mainly based on their concerns regarding the potential consequences of the nanotechnologies. They were able to assess potential consequences and define suggestions for solving these, on different levels of abstraction, including the personal, societal, and to a lesser extent, technological level. The underlying motives of the concerns and suggestion were based on various values, such as well-being, autonomy, privacy, affordability, safety and health. The importance of these values differed per technology aspect. Our study shows that citizens can provide valuable contributions to the development and implementation of emerging technologies at an early stage. Citizens are able to approach these technologies in a multi-dimensional way. Hence, when designing, developing and implementing nanotechnologies for health, involved actors, such as policymakers, researchers and CSOs could include citizens as valuable partners in identifying potential users' and societal concerns and collecting suggestions for addressing these concerns. When setting-up citizen engagement activities, it is important that the nanotechnologies are presented in a way that citizens can relate to them, which goes beyond the mere technological aspects of the technologies. This could be done by making analogies with existing technologies.

\section{Appendix. Scenarios focus groups}

The scenarios below were created by the Danish Board of Technology Foundation in collaboration with the authors of this article as part of the EU Horizon 2020 project GoNano. More information can be found in the project's deliverable 3.1. ${ }^{1}$

\footnotetext{
${ }_{1}$ Bitsch, L. (2018). Deliverable 3.1 of the GoNano project: R\&I production for pilot studies. Retrieved from: http:// gonano-project.eu/wp-content/uploads/2019/01/D3.1-RIbackground-production-1.pdf
} 


\section{Scenario 1}

\section{MONITORING FOR (UN)HEALTHY CONTROL?}

Sofia turns off the alarm clock, yawns and finally sits up. Time to get up. She turns off the flight mode on her phone, turns on the Bodysensor app and holds her breath for a few seconds as it updates. Then she sighs. No signs of cancer. Yet. Time to wake up the kids. Since they installed nanorobot sensors in her breasts it has become a daily routine for Sofia to check the Bodysensor app first thing in the morning. Her mother died of breast cancer seven years ago. Apparently Sofia is also genetically predisposed to develop breast cancer. The nanorobot sensors were offered to her in order to detect eventual cancer cells as early as possible. As Sofia sets the table for breakfast, she thinks of her mother. If only her cancer had developed five years later, she would most likely have survived. Since the development of cancer treatments enhanced with nanotechnology, very few die from breast cancer, and no-one has to suffer from the terrible side effects of the out-dated chemotherapies and radiotherapies of the past. Today, they use tiny nanorobots to transport the therapeutic agents directly to the tumour, so that patients do not need to have their entire body bombarded with chemicals and radiation. Tiny nanosensors are installed in the breast tissue of cancer patients that kept track of how they react to the treatment. In this way doctors can make adjustments as soon as it is needed - and monitor any recurrence of tumour cells. Peter is getting the kids ready. Sofia sits down with a cup of coffee. She looks at her phone and fights the temptation to check the Bodysensor app. The app is her safety net, but also a daily reminder that one day the figures might not be as she hoped. And what if the app doesn't detect everything? What if someone hacks into her phone and changes the settings or reads her data? Before the nanosensors were installed, Sofia didn't think much about cancer. Now she thinks about it all the time. Peter comes in with the kids, and they all sit down to have breakfast. Sofia is grateful to be alive.

\section{Scenario 2}

\section{SMELLING DISEASE}

John is sitting in front of a computer at the pharmacy for his yearly health check-up. The yearly check-up is mandatory for everyone above the age of 30 . On the computer screen in front of him, he has a view of a doctor sitting in front of a desk looking into a computer screen. On John's side of the screen there is a mechanical device that looks a bit like a nose. An assistant cleans the noselike device and asks John to open his mouth and take the device into it and blow his breath back and forth for a minute. The artificial nose can detect many types of disease. It takes 15 minutes for the doctor to return with the test results. As he waits, John speculates about all the different types of diseases he might have - hasn't he been a bit more tired lately, and what about the other day when he suddenly couldn't remember the name of one of his colleagues? He is scared be might be developing a mental health disorder like dementia or Alzheimer's disease, or neurological disease like ALS where your muscles slowly die. Imagine not knowing when or how the disease would develop. John knows that medications today are much better than they used to be - but what was it he read the other day, about some medications only working well for some people and not for others? Was it that people of African descent who had the worst coverage with the new medications? The doctor returns to the screen. John's stomach is twisted up in a hard uneasy knot as he waits for the news. John is fine. 


\section{Scenario 3}

\section{DOCTOR AT HOME}

Sofia is sitting on the toilet in her bathroom at home. She is opening the package of a new home test for diabetes. The test is a needle with a nanochip. She will need to prick her finger to provide a blood drop for analysis on the nanochip. The chip can immediately detect if Sofia suffers from diabetes 1 or 2 . Recently, Sofia has felt very tired and thirsty and she constantly had to go the toilet. She searched online to check her symptoms and ended up on a webpage about diabetes. The website also described different treatment options. One option is a small wearable device developed using nanotechnology. This device constantly measures the level of insulin, and injects extra insulin when needed. Another option is to create new beta cells in the body. With diabetes type 1, beta cells in the body stop working. Using nanotechnology, doctors are able to create new beta cells from stem cells, and place those in the body. No other medication is needed. Sofia considers her situation. She is already happy the home test for diabetes was cheap and easy to buy. Since health insurance does not cover check-ups at the general practitioner anymore, home tests are very useful. She is a little uncertain about using the needle to prick her finger. What if she has diabetes? What treatment option would she choose? She imagines having to carry around a small device for the rest of her life. What if it breaks down or has errors? How would she know she was getting the right amount of insulin? The beta cells created from her own stem cells would cure her diabetes. She would never need to think about it again. But her insurance does not cover the treatment, and it is very expensive. She also wonders how her religious community would feel about such a treatment. Would it be allowed? She takes a deep breath and pricks her finger with the needle.

Acknowledgements We wish to thank all the partners of the GoNano-project for the fruitful collaboration during the project and their valuable input regarding the development and design of the co-creation methodology. These partners include the Danish Board of Technology Foundation, De Proeffabriek, the Oslo Metropolitan University, the Technology Centre CAS, the Italian Association for Industry Research, the Institute of Technology Assessment, the Center for International Environmental Law, the European Institute of Women's Health and RMIT Europe. Furthermore, we want to thank the participants for their contributions during the focus group sessions and the moderators for their guiding these sessions.

Funding This research took place in the context of the GoNano project. This project has received funding from the European Union's Horizon 2020 research and innovation program under grant agreement no. 768622.

\section{Declarations}

Ethical Approval Ethical approval from this study was obtained from the Ethics Committee BMS domain Humanities and Social Sciences of the University of Twente.

Conflict of Interest The authors declare no competing interests.

Open Access This article is licensed under a Creative Commons Attribution 4.0 International License, which permits use, sharing, adaptation, distribution and reproduction in any medium or format, as long as you give appropriate credit to the original author(s) and the source, provide a link to the Creative
Commons licence, and indicate if changes were made. The images or other third party material in this article are included in the article's Creative Commons licence, unless indicated otherwise in a credit line to the material. If material is not included in the article's Creative Commons licence and your intended use is not permitted by statutory regulation or exceeds the permitted use, you will need to obtain permission directly from the copyright holder. To view a copy of this licence, visit http://creativecommons.org/licenses/by/4.0/.

\section{References}

1. Jasanoff S (2014) A mirror for science. Public Underst Sci 23(1):21-26. https://doi.org/10.1177/0963662513505509

2. Wynne B (2006) Public engagement as a means of restoring public trust in science: Hitting the notes, but missing the music? Community Genet 9(3):211-2020

3. Rip A (2014) The past and future of RRI. Life Sci Soc Policy 10:1-15. https://doi.org/10.1186/s40504-014-0017-4

4. Schuijer JW, Broerse JEW, Kupper F (2021) Citizen science fiction: The potential of situated speculative prototyping for public engagement on emerging technologies. NanoEthics 15:1-18. https://doi.org/10.1007/ s11569-020-00382-4

5. Pidgeon N (2021) Engaging publics about environmental and technology risks: Frames, values and deliberation. J Risk Res 24(1):28-46. https://doi.org/10.1080/13669877. 2020.1749118 
6. Krabbenborg L (2012) The potential of national public engagement exercises: Evaluating the case of the recent Dutch societal dialogue on nanotechnology. Int J Emerg Technol Soc 10:27-44

7. Bucchi M, Neresini F (2008) Science and public participation. In: Hackett EJ, Amsterdamska O, Lynch M, Wajcman J (eds) The handbook of science and technology studies, 3rd edn. MIT press, Cambridges (MA), pp 449-474

8. Wilsdon J, Willis R (2004) See-through science: Why public engagement needs to move upstream. Demos, London

9. Hennen L, Pfersdorf S (2014) Public engagement: Promises, demands and fields of practice. Engaging society in Horizon 2020 - Engage2020

10. Russel AW (2013) Improving legitimacy in nanotechnology policy development through stakeholder engagement: Forging new pathways. Rev Policy Res 30(5):566-588. https://doi.org/10.1111/ropr.12037

11. Von Schomberg R (2012) Prospects for technology assessment in a framework of responsible research and innovation. In: Dusseldorp M, Beecroft R (eds) Technikfolgen Abschätzen Lehren: Bildungspotenziale Transdisziplinärer. VS Verlag für Sozialwissenschaften, Wiesbaden, pp 39-61

12. European Commission (2016) Public engagement in responsible research and innovation. https://ec-europa-eu.ezproxy2. utwente.nl/programmes/horizon2020/en/h2020section/ publicengagemenresponsible-research-and-innovation. Accessed 25 Nov 2020

13. Gudowsky N, Peissl W (2016) Human centred science and technology - transdisciplinary foresight and cocreation as tools for active needs-based innovation governance. European J Future Res 4(8):1-10. https://doi.org/ 10.1007/s40309-016-0090-4

14. Gudowsky N, Sotoudeh M (2017) Into blue skies - a transdisciplinary foresight and co-creation method for adding robustness to visioneering. NanoEthics 11:93-106. https://doi.org/10.1007/s11569-017-0284-7

15. Polk M (2015) Transdisciplinary co-production: Designing and testing a transdisciplinary research framework for societal problem solving. Futures 65:110-122. https://doi. org/10.1016/j.futures.2014.11.001

16. Voorberg WH, Bekkers VJJM, Tummers LG (2015) A systematic review of cocreation and co-production: Embarking on the social innovation journey. Public Manag Rev 17(9):1333-1357. https://doi.org/10.1080/ 14719037.2014.930505

17. Von Hippel E (2005) Democratizing innovation. MIT press, Cambridges (MA)

18. Prahalad CK, Ramaswamy V (2004) The future of competition. School Press, Boston (MA), Harvard Business

19. Vargo SL, Lusch RF (2004) The four marketing myths: Remnants of goods-based, manufacturing model. J Serv Res 6(4):324-335. https://doi.org/10.1177/1094670503262946

20. Pittens CACM, Vonk Noordegraaf AV, van Veen SC, Anema JR, Huirne JAF, Broerse JEW (2013) The involvement of gynecological patients in the development of a clinical guideline for resumption of (work) activities in the Netherlands. Health Expect 18:1397-1412. https://doi. org/10.1111/hex.12121

21. Braun K, Schultz S (2010) A certain amount of engineering involved?: Constructing the public in participatory governance arrangements. Public Underst Sci 19(4):403419. https://doi.org/10.1177/0963662509347814

22. Arentshorst ME, de Cock BT, Broerse JEW (2016) Exploring responsible innovation: Dutch perceptions of the future medical neuroimaging technology. Technol Soc 45:8-18. https://doi.org/10.1016/j.techsoc.2016.01.003

23. Goisauf M, Durnová AP (2019) From engaging publics to engaging knowledges: Enacting "appropriateness" in the Austrian biobank infrastructure. Public Underst Sci 28(3):275-289. https://doi.org/10.1177/0963662518806451

24. Lehoux P, Miller FA, Grimard D, Gauthier P (2018) Anticipating health innovations in 2030-2040: Where does responsibility lie for the publics? Public Underst Sci 27(3):276-293. https://doi.org/10.1177/0963662517725715

25. Repo P, Matschoss K (2019) Considering expert takeovers in citizen involvement processes. J Responsible Innov 6(2):119 142. https://doi.org/10.1080/23299460.2019.1568145

26. De Saille S (2015) Innovating innovation policy: The emergence of 'responsible research and innovation.' J Responsible Innov 2(2):152-168. https://doi.org/10.1080/ 23299460.2015.1045280

27. Delgado A, Kjolberg KL, Wickson F (2011) Public engagement coming of age: From theory to practice in STS encounters with nanotechnology. Public Underst Sci 20(6):826-845

28. Mangematin V, Walsh S (2012) The future of nanotechnologies. Technovation 32:157-160. https://doi.org/10. 1016/j.technovation.2012.01.003

29. Foley R, Wiek A, Kay B (2017) Nanotechnology development as if people and places matter. NanoEthics 11(3):243257. https://doi.org/10.1007/s11569-017-0300-y

30. Dijkstra AM, Critchley C (2016) Nanotechnology in Dutch science cafés: Public risk perceptions contextualized. Public Underst Sci 25(1):71-87. https://doi.org/10. 1177/0963662514528080

31. Wickson F, Delgado A, Kjolberg KL (2010) Who or what is 'the public'? Nat Nanotechnol 5:757-758

32. Shelley-Egan C, Bowman DM, Robinson DKR (2018) Devices of responsibility: Over a decade of responsible research and innovation initiatives for nanotechnologies. Sci Eng Ethics 24(6):1719-1746. https://doi.org/10.1007/ s11948-0179978z

33. Majmudar MD, Colucci LA, Landman AB (2015) The quantified patient of the future: Opportunities and challenges. Healthcare 3(3):153-156. https://doi.org/10.1016/j. hjdsi.2015.02.001

34. Sittig DF, Singh H (2010) A new socio-technical model for studying health information technology in complex adaptive healthcare systems. Qual Saf Health Care 19:6874. https://doi.org/10.1136/qshc.2010.042085

35. Bergek A, Jacobsson S, Carlsson B, Lindmark S, Rickne A (2008) Analyzing the functional dynamics of technological innovation systems: A scheme of analysis. Res Policy 37:407-429. https://doi.org/10.1016/j.respol.2007.12.003

36. Wickson F, Forsberg E-M (2015) Standardising responsibility? The significance of interstitial spaces. Sci Eng Ethics 21:1159-1180. https://doi.org/10.1007/s11948-014-9602-4

37. Porcari AM, Pimponi D, Borsella E, Mantovani, E (2019) PRISMA RRI-CSR Roadmap. EU Horizion 2020 - Prisma

38. Tohidi M, Buxton W, Baecker R, Sellen A (2006) Getting the right design and the design right: Testing many is 
better than one. CHI 2006 Conference: Usability Methods Montreal, pp 1243-1252. Retrieved from: https://www. billbuxton.com/rightDesign.pdf

39. Yoo D, Huldtgren A, Woelfer JP, Hendry DG, Friedman B (2013) A value sensitive action-reflection model: Evolving co-design space with stakeholder and designer prompts. CHI 2013 Conference: Changing perspectives. Paris, pp 419-428. Retrieved from: https://vsdesign.org/publications/ pdf/p419-yoo.pdf

40. Wilkinson C, Anderson A, Petersen A (2007) From uncertainty to risk? Scientific and news media portrayals of nanoparticle safety. Health Risk Soc 9:145-157. https:// doi.org/10.1080/13698570701306823

41. Capon A, Gillespie J, Rolfe M, Smith W (2015) Perceptions of risk from nanotechnologies and trust in stakeholders: A cross sectional study of public, academic, government and business attitudes. BMC Public Health 15:424-437. https://doi.org/10.1186/s12889-015-1795-1

42. Cacciatore MA, Dietram A, Scheufele DA, Corley EA (2011) From enabling technology to application: The evolution of risk perceptions of nanotechnology. Public Underst Sci 20(3):384 404. https://doi.org/10.1177/0963662509347815
43. Bottini M, Rosato N, Gloria F, Adanti S, Corradino N (2011) Public optimism towards nanomedicine. Int $\mathbf{J}$ Nanomed 6:3473-3485. https://doi.org/10.2147/ijn.s26340

44. Davies SR (2011) How we talk when we talk about nano: The future in laypeople's talk. Futures 43:317-326

45. Marcu GR, Rutsaert P, Seibt B, Fletcher D, Verbleke W, Barnett J (2014) Analogies, metaphors, and wondering about the future: Lay sense-making around synthetic meat. Public Underst Sci 24(5):547-562. https://doi.org/ $10.1177 / 0963662514521106$

46. Schwarz-Plaschg C (2018) Nanotechnology is like... the rhetorical role of analogies in public engagement. Public Underst Sci 27(2):153-167. https://doi.org/10.1177/0963662516655686

47. Jansma SR, Dijkstra AM, de Jong MDT (forthcoming) Co-creation in support of responsible research and innovation: An analysis of three stakeholder workshops on nanotechnology for health. J Responsible Innov

Publisher's Note Springer Nature remains neutral with regard to jurisdictional claims in published maps and institutional affiliations. 